\title{
PENGETAHUAN BERPENGARUH TERHADAP KEPATUHAN DALAM PERAWATAN KAKI PADA KLIEN DIABETES MELITUS TIPE II
}

\author{
Dian Hudiyawati ${ }^{1}$, Sabila Rizki \\ ${ }^{1,2}$ Universitas Muhammadiyah Surakarta, Program Studi Keperawatan \\ Diterima : 22 November 2018, Disetujui : 30 November 2018 \\ e-mail :dh202@ums.ac.id
}

\begin{abstract}
Background: An increasing number of people with diabetes mellitus will increase the risk of chronic complications, one of which is neuropathy. Diabetic neuropathy can cause disability and even death. Management of Diabetes Mellitus is intended to prevent the occurrence of complications by educating clients about foot care. it aims to improve the knowledge and adherence of people with diabetes mellitus. The purpose of this study was to determine the relationship of knowledge level of foot care with adherence in performing foot care in patients with Type II Diabetes Mellitus. Research Methods. this study was a quantitative research using descriptive analytic method through a cross sectional study approach. Data analysis used Chi-Square. This research questionnaire used Nottingham Assessment of Functional Footcare (NAFF) to measure knowledge Rnd Diabetic Foot Care Behavior (DFCB) to measure compliance. Results showed a significant relationship between the level of knowledge with patient compliance in performing foot care $(p=0.001)$. Conclusion, Based on these results can be concluded that people with diabetes mellitus who have good knowledge will tend to increase adherence in performing foot care.
\end{abstract}

Keywords: Diabetes Mellitus Type II, Knowledge, Compliance, Foot Care.

\section{PENDAHULUAN}

Diabetes Melitus merupakan gangguan metabolisme kronis yang berkontribusi pada peningkatan kadar glukosa (Hiperglikemia). Kadar glukosa dalam darah yang mengalami peningkatan dalam jangka waktu yang lama merupakan efek umum dari diabetes tak terkontrol, dimana pada tingkat tertentu dapat menyebabkan kerusakan serius pada sistem tubuh, khususnya pada sistem saraf dan pembuluh darah (World Health Organization, 2016). Pada tahun 2012 Diabetes Melitus merupakan penyebab kematian kedelapan dan tingginya kadar gula dalam darah bertanggungjawab atas 3,7 juta kematian dunia (WHO, 2016). Menurut International Diabetes Federation (IDF) (2015) Indonesia merupakan negara urutan ke 7 dengan jumlah 10 juta penderita Diabetes Melitus. Kota Surakarta berada di urutan ke 10 dengan prevalensi 274 penderita IDDM dan 5223 penderita NIDDM (Dinas Kesehatan Provinsi Jawa Tengah, 2016).

Perkumpulan Endokrinologi Indonesia (PERKENI) (2015) menyatakan bahwa komplikasi yang terjadi pada penderita Diabetes Melitus dibagi menjadi dua yaitu komplikasi akut dan komplikasi kronis. Komplikasi kronis yang terjadi pada penderita Diabetes Melitus salah satunya neuropati. Menurut Purwanti 
(2013), di Indonesia terdapat 1785 penderita Diabetes Melitus yang sudah mengalami komplikasi seperti, neuropati $(63,5 \%)$. Tingginya prevalensi penderita Diabetes Melitus yang mengalami komplikasi neuropati dapat meningkatkan resiko terjadinya kerusakan pembuluh darah perifer tungkai yang biasa disebut dengan kaki diabetik (PERKENI, 2015).

Kaki diabetik (Diabetic Foot) merupakan salah satu infeksi kronik yang paling ditakuti oleh penderita Diabetes Melitus (Natovich, Harman-Boehm, Margalit, Cukierman-Yaffe \& Kushnir, 2017). Komplikasi ini dapat menyebabkan kecacatan dan memiliki resiko 15 sampai 40 kali lebih besar terjadi amputasi dengan prevalensi sekitar 25\% di bandingkan dengan non Diabetes Melitus, bahkan sampai terjadinya kematian karena ulkus diabetikum dengan prevalensi kejadian sekitar 16\% (Muflihatin \& Saputra, 2016; Wahyuni \& Arisfa, 2016; Waspadji, 2014). Sebagian besar merupakan amputasi minor yaitu bagian dibawah pergelangan kaki dengan prevalensi $64,7 \%$ dan amputasi mayor 35,3\% (Purwanti \& Nurhayati, 2017). Penderita Diabetes Melitus yang dirawat karena komplikasi pada kaki memiliki prevalensi $15 \%$ sampai 20\% (Frykberg et al., 2000).

Pengelolaan Diabetes Melitus dalam upaya pencegahan terjadinya ulkus kaki diabetik salah satunya dengan melakukan edukasi atau pendidikan kesehatan tentang perawatan kaki (PERKENI, 2015). Menurut penelitian yang dilakukan oleh Khamseh, Vatankhah \& Baradaran (2007) mengungkapkan bahwa kurangnya pengetahuan pasien tentang perawatan kaki menjadi salah satu hambatan bagi penderita Diabetes Melitus dalam melaksanakan perawatan kaki.

Salah satu upaya preventif pada penderita Diabetes Melitus dalam mencegah ulkus pada kaki adalah dengan melakukan perawatan kaki (Deepa, Murty, Reddy \& Shetty, 2017). Perawatan kaki yang tepat merupakan bagian penting dari proses pencegahan penyakit ulkus kaki diabetik yang dapat dilakukan oleh penderita Diabetes Melitus dengan biaya yang murah dan efektif (Moussa, Moussaandnaglaa \& Mohamed, 2017). Perawatan kaki yang dilakukan setiap hari memungkinkan penderita Diabetes Melitus untuk mendeteksi secara dini kelainan dan luka pada kaki, sehingga dapat melakukan tindakan pencegahan atau bahkan mengurangi risiko ulserasi kaki secara efektif (Hokkam, 2009).

Menurut penelitian Yoyoh, Mutaqqijn \& Nurjanah (2016) kepatuhan pasien dalam perawatan atau mengatur dirinya melalui melakukan pencegahan luka dengan perawatan kaki seperti yang telah disarankan oleh tenaga kesehatan dalam mencapai keberhasilan dalam penatalaksanaan Diabetes Melitus, diperlukan kepatuhan yang cukup baik dari penderita Diabetes Melitus itu sendiri. Hal tersebut sesuai dengan hasil penelitian yang dilakukan oleh Putri \& Isfandiari (2013) diketahui bahwa 41,5\% penderita Diabetes Melitus yang memiliki tingkat kepatuhan baik menunjukan kadar gula dalam darah < $160 \mathrm{mg} / \mathrm{dl}$, sedangkan 26,4 $\%$ penderita diabetes melitus memilki tingkat kepatuhan yang kurang dengan kadar gula dalam darah > $160 \mathrm{mg} / \mathrm{dl}$.

Berdasarkan uraian diatas perlu dilakukan penelitian mengenai hubungan antara pengetahuan dengan tingkat kepatuhan dalam melakukan perawatan 
kaki pada penderita Diabetes Melitus Tipe II.

\section{METODE PENELITIAN}

Penelitian ini termasuk dalam jenis penelitian kuantitatif. Desain penelitian yang digunakan adalah deskriptif analitik dengan pendekatan cross sectional study. Penelitian dilakukan di Persatuan Diabetes Melitus Surakarta (PADIMAS). Pelaksanaan penelitian dimulai pada bulan November 2017 sampai Mei 2018. Populasi dalam penelitian ini adalah semua penderita Diabetes Melitus yang terdaftar sebagai anggota aktif di PADIMAS dengan jumlah sampel yang didapatkan adalah 37 responden dengan menggunakan metode purposive sampling. Kriteria responden dalam penelitian ini yaitu pasien yang telah mendapatkan Pendidikan perawatan kaki DM dan tidak mengalami ulkus diabetik.

Terdapat dua jenis variabel penelitian, yaitu variabel independent (tingkat pengetahuan perawatan kaki) dan variabel dependen (kepatuhan klien dalam melakukan perawatan kaki). Kuesioner untuk mengukur tingkat kepatuhan klien dalam melakukan perawatan kaki menggunkan kuesioner Diabetic Functional Care Behaviour (DFBC), sedangkan kuesioenr tingkat pengetahuan menggunakan Nottingham Assessment Functional Footcare (NAFF). DFBC merupakan kuesioner observasi praktik perawatan kaki yang berisi 14 item observasi yang meliputi 6 poin perawatan kaki. Untuk lembar observasi DFCB, jawaban tidak diberi skor 0 , jawaban ya diberi skor 1 . Skala pengkategoriannya yaitu: (1) patuh, jika responden memperoleh skor $7-14$; (2) tidak patuh, jika responden memperoleh skor 0-6. Hasil dari uji reliabilitas yang di lakukan oleh peneliti sendiri pada kuesioner DFCB berisi 15 item pertanyaan nilai Cronbach Alpha 0,879 sedangkan untuk kuesioner NAFF dengan 29 item pertanyaan nilai Cronbah Alpha 0,755.

Analisis data univariat digunakan untuk mendeskripsikan data sosiodemografi klien yang berupa usia, jenis kelamin, tingkat pendidikan dan lama menderita DM. Analisis bivariat menggunakan uji chi-square untuk mengetahui hubungan antara pengetahuan dan kepatuhan klien dalam melakukan perawatan kaki DM.

Proses pengambilan data dilakukan dengan pemilihan responden yang digunakan untuk penelitian disesuaikan dengan karakteristik responden dengan teknik purposive sampling dan tersisa 37 responden. Meminta kesediaan responden yang telah menjadi sampel dengan menjelaskan maksud dan tujuan penelitian tersebut dengan mengisi informed consent. Peneliti dan enumerator melakukan pendampingan kepada para responden selama pengisian kuesioner. Mengumpulkan kuesioner yang telah diisi oleh responden yang menjadi sampel dalam penelitian. Memeriksa ulang kelengkapan jawaban dalam kuesioner yang dibagi kepada para responden. Selanjutnya jika kuesioner sudah lengkap dan sesuai dengan aturan dalam menjawab pertanyaan maka data yang terkumpul akan diolah dan dianalisa sesuai dengan teknik analisa yang sudah ditetapkan dengan menggunakan aplikasi untuk uji statistik. 
HASIL PENELITIAN

Tabel 1. Gambaran Karakteristik Pada Penderita Diabetes Melitus Tipe II

\begin{tabular}{|c|c|c|c|}
\hline & Karakteristik Responden & Frekuensi (N) & Presentase $(\%)$ \\
\hline \multicolumn{4}{|c|}{ 1. Jenis Kelamin } \\
\hline & Laki-laki & 15 & 40.5 \\
\hline & Perempuan & 22 & 59.5 \\
\hline & Total & 37 & 100.0 \\
\hline \multirow[t]{6}{*}{2.} & Usia & & \\
\hline & $36-45$ & 1 & 2.7 \\
\hline & $46-55$ & 10 & 27.0 \\
\hline & $56-65$ & 20 & 54.1 \\
\hline & $>65$ & 6 & 16.2 \\
\hline & Total & 37 & 100.0 \\
\hline & Lama Menderita & & \\
\hline & $1-5$ & 17 & 45.9 \\
\hline & $6-10$ & 20 & 54.1 \\
\hline & Total & 37 & 100.0 \\
\hline \multirow[t]{7}{*}{4.} & Pendidikan Terkahir & & \\
\hline & $\mathrm{SD}$ & 7 & 18.9 \\
\hline & SMP & 9 & 24.3 \\
\hline & SMA & 13 & 35.1 \\
\hline & $\mathrm{S} 1$ & 7 & 18.9 \\
\hline & $\mathrm{S} 2$ & 1 & 2.7 \\
\hline & Total & 37 & 100.0 \\
\hline
\end{tabular}

Tabel 2. Gambaran Tingkat Pengetahuan Perawatan Kaki Pada Penderita Diabetes Melitus Tipe II.

\begin{tabular}{lcc}
\hline \multicolumn{1}{c}{ Tingkat Pengetahuan } & Frekuensi $(\mathrm{N})$ & Persentase $(\%)$ \\
\hline Kurang & 9 & 24.3 \\
Baik & 28 & 75.7 \\
Total & 37 & 100.0 \\
\hline
\end{tabular}

Tabel 3. Gambaran Kepatuhan Dalam Melakukan Perawatan Kaki

\begin{tabular}{lcc}
\hline Tingkat Kepatuhan & Frekuensi (N) & Persentase (\%) \\
\hline Tidak Patuh & 10 & 27.0 \\
Patuh & 27 & 73.0 \\
Total & 37 & 100.0 \\
\hline
\end{tabular}


Tabel 4. Hubungan Tingkat Pengetahuan Perawatan Kaki Dengan Kepatuhan Dalam Melakukan Perawatan Kaki Pada Penderita Diabetes Melitus Tipe II

\begin{tabular}{lcccccccc}
\hline \multirow{2}{*}{$\begin{array}{c}\text { Tingkat } \\
\text { Pengetahuan }\end{array}$} & \multicolumn{9}{c}{ Tidak Patuh } & \multicolumn{2}{c}{ Patuh } & \multicolumn{2}{c}{ Total } & Chi- & Square & $\mathrm{p}$ \\
\cline { 2 - 7 } & $(\mathrm{N})$ & $(\%)$ & $(\mathrm{N})$ & $(\%)$ & $(\mathrm{N})$ & $(\%)$ & & \\
\hline Kurang & 9 & $24.3 \%$ & 0 & $0.0 \%$ & 9 & $24.3 \%$ & & \\
Baik & 1 & $2.7 \%$ & 27 & $73.0 \%$ & 28 & $75.7 \%$ & 32.111 & 0.001 \\
Total & 10 & $27.0 \%$ & 27 & $73.0 \%$ & 37 & $100.0 \%$ & & \\
\hline
\end{tabular}

\section{PEMBAHASAN}

\section{Usia}

Distribusi karakteristik responden penderita Diabetes Melitus berdasarkan usia memiliki frekuensi tertinggi pada kelompok umur 56-65 tahun yang berjumlah 20 orang (54.1\%). Distribusi umur responden menunjukan sebagian besar responden merupakan kelompok lansia. Diabetes Melitus Tipe II biasanya terjadi pada usia dewasa (adult or maturity onset diabetes) (Mulyadi, Rahman, Rosadi, Khairiyati, \& Musafaah, 2013). Usia lebih dari 40 tahun adalah usia yang beresiko terkena Diabetes Melitus Tipe II dikarenakan adanya intoleransi glukosa dan terjadinya proses penuaan yang menyebabkan gangguan pada sel $\beta$ di pankreas dalam memproduksi insulin (Trisnawati \& Setyorogo, 2013). Penelitian ini memiliki kesamaan dengan Sholihah (2014) yang menyatakan bahwa semakin tinggi usia penderita Diabetes Melitus Tipe II, maka akan semakin tinggi kadar glukosa darah yang disebabkan gangguan toleransi glukosa.

\section{Jenis kelamin}

Karakteristik responden menurut jenis kelamin menunjukan frekuensi tertinggi adalah perempuan dengan jumlah 22 orang (59.5\%). Hal ini sesuai dengan penelitian yang dilakukan oleh
Taylor (2010) bahwa perempuan mengalami kondisi penurunan produksi hormon esterogen yang terjadi pada masa menopause yang menjadi penyebab utama menderita Diabetes Melitus. Perempuan lebih berisiko terkena Diabetes Melitus tipe 2 karena secara fisik wanita memiliki peluang mengalami peningkatan indeks masa tubuh yang lebih besar. Sindroma siklus bulanan (premenstrual syndrome), pasca-menopouse yang membuat distribusi lemak tubuh menjadi mudah terakumulasi akibat proses hormonal tersebut sehingga wanita berisiko menderita Diabetes Melitus Tipe II (Sukmaningsih, 2016).

\section{Lama Menderita DM}

Karakteristik responden menurut lama menderita Diabetes Melitus dengan distribusi tinggi pada durasi 6-10 tahun berjumlah 20 orang (54.1\%). Semakin lama menderita Diabetes Melitus maka akan akan meningkatkan resiko terjadinya komplikasi pada tubuh, maka responden dengan durasi lebih lama menderita Diabetes Melitus juga akan lebih banyak mendapatkan beberapa informasi atau pendidikan kesehatan tentang perawatan kaki sebagai tindakan pencegahan dari komplikasi kaki diabetik.

\section{Tingkat Pendidikan}

Berbeda dengan penelitian yang dilakukan oleh Allorerung, Sekeon, \& 
Joseph (2016) didapatkan hasil yang menyatakan bahwa tidak ada hubungan antara tingkat pendidikan dengan kejadian Diabetes Melitus Tipe II dengan nilai $P$-value 0,723 jumlah tingkat pendidikan rendah adalah $87 \%$. Peneliti berasumsi bahwa pada tingkat pendidikan yang rendah akan memengaruhi proses penerimaan informasi atau pendidikan kesehatan yang disampaikan oleh para petugas kesehatan maupun dari media sosial. Tingkat pengetehuan akan mempengaruhi tingkat pengetahuan seseorang.

\section{Hubungan Pengetahuan dengan Tingkat kepatuhan Perawatan Kaki Penderita DM tipe II}

Hasil penelitian menunjukkan bahwa terdapat hubungan yang signifikan antara pengetahuan dengan kepatuhan dalam melakukan perawatan kaki pada penderita Diabetes Melitus Tipe II. Hasil penelitian yang dilakukan oleh Diani et al., (2013) menunjukkan bahwa penderita Diabetes Melitus Tipe II yang pernah mendapatkan pendidikan kesehatan memiliki praktik perawatan kaki lebih baik dibandingkan dengan yang tidak pernah mendapatkan pendidikan kesehatan.

Berdasarkan hasil penelitian yang dilakukan didapatkan hasil responden dengan pengetahuan baik lebih besar jumlahnya di bandingkan dengan responden yang memilki tingkat pengetahuan kurang yaitu berjumlah 28 responden $(75.5 \%)$ dari 37 responden (100\%). Hasil penelitian dilakukan oleh Lis, Gandini, Pranggono, \& Ropi (2015) yaitu penerapan pendidikan kesehatan oleh perawat dapat meningkatkan pengetahuan dan perilaku pasien Diabetes Melitus Tipe II.
Hasil penelitian ini sama dengan Diani et al., (2013) yang menyatakan menunjukan terdapat hubungan yang signifikan antara pengetahuan dengan kepatuhan dalam melakukan perawatan kaki pada penderita Diabetes Melitus Tipe II. Penderita Diabetes Melitus yang berpengetahuan baik berpeluang 2,44 kali patuh dalam melakukan perawatan kaki di bandingkan dengan penderita Diabetes Melitus Tipe II yang berpengetahuan kurang (Diani et al., 2013).

Namun berbeda dengan penelitian yang dilakukan oleh Lukitasari (2013) yang menyatakan bahwa tidak terdapat hubungan antara tingkat pengetahuan dengan kepatuhan. Delamater (2006) \& Niven (2008) dalam Windasari (2014) menyatakan bahwa pengetahuan merupakan dasar dari perubahan perilaku individu serta menentukan tingkat kemampuan individu dalam melakukan perawatan secara mandiri.

Penderita Diabetes Melitus yang memiliki tingkat pengetahuan perawatan kaki baik tetapi tidak patuh dalam melakukan perawatan kaki dalam penelitian ini dimungkinkan terjadi karena faktor variabel pengganggu yang tidak di kontrol ataupun sikap acuh dari penderita Diabetes Melitus (Lukitasari, 2013). Hal ini mungkin disebabkan karena banyaknya faktor lain yang mempengaruhi kepatuhan pasien dalam melakukan manajemen Diabetes Melitus selain pengetahuan. Menurut penelitian yang dilakukan oleh Alfian (2016) faktor lain yang dapat mempengaruhi kepatuhan adalah tingkat keparahan penyakit dan adanya intervensi langsung dari tenaga kesehatan untuk melakukan manajemen Diabetes Melitus.

Penderita Diabetes Melitus yang memiliki tingkat pengetahuan yang baik 
juga memiliki kepatuhan dalam melakukan perawatan kaki karena kebiasaan akan terbentuk oleh pengetahuan yang dimiliki terutama kebiasaan tentang cara perawatan kaki (Diani et al., 2013). Kepatuhan merupakan suatu perubahan perilaku yang tidak mentaati peraturan ke perilaku yang mentaati peraturan. Proses perubahan perilaku juga didasarkan oleh pengetahuan. Perilaku yang didasarkan oleh pengetahuan akan lebih langgeng di banding perilaku yang tidak didasarkan oleh pengetahuan (Notoatmodjo 2010).

Melalui pendidikan kesehatan penderita Diabetes Melitus dapat memperoleh infromasi yang memadai dari petugas kesehatan serta di harapkan mampu meningkatkan pengetahuan dan kepatuhan dalam melakukan perawatan kaki untuk mencegah terjadinya komplikasi salah satunya kaki diabetik (Bodenheimer, Davis, \& Holman, 2007). Diharapkan dengan adanya pendidikan yang berkesinambungan di harapkan mampu meningkatkan pengetahuan dan kepatuhan dalam melakukan perawatan kaki secara rutin setiap harinya secra mandiri untuk menciptakan serta meningkatkan kwalitas hidup penderita Diabetes Melitus.

\section{KESIMPULAN DAN SARAN}

Berdasarkan hasil pembahasan dapat disimpulkan bahwa pengetahuan merupakan salah satu factor yang tidak dapat diabaikan dalam melakukan perawatan mandiri pada penderita DM tipe II. Pengathuan terbukti memiliki pengaruh yang signifikan terhadap tingkat kepatuhan penderita DM Tipe II dalam melakukan perawatan kaki.

Beberapa saran yang dapat disampaikan berdasarkan hasil penelitian untuk penelitian selanjutnya yaitu peneliti selanjutnya bisa meneliti tentang faktor lain yang dapat mempengaruhi kepatuhan dalam melakukan perawatan kaki agar meningkatkan wawasan dan informasi tentang Diabetes Melitus Tipe II.

\section{DAFTAR RUJUKAN}

Alfian, R. (2016). Kepatuhan Tentang Penggunaan Insulin Pada Pasien Diabetes Mellitus Di Poliklinik Banjarmasin Correlation Between The Knowledge And The Adherence In Diabetes Mellitus Patients Using Insulin At Internal Disease Polyclinic. Jurnal Ilmiah Ibnu Sina, 1(1), 9-18.

Allorerung, D., Sekeon, S., \& Joseph, W. (2016). Hubungan Antara Umur, Jenis Kelamin, Tingkat Pendidikan Dengan Kejadian Diabetes Melitus Tipe 2 Di Puskemas Ranotana Weru Kota Manado Tahun 2016, $1-8$.

Bodenheimer, T., Davis, C., \& Holman, H. (2007). Helping Patients Adopt Healthier Behaviors. Clinical Diabetes (Vol. 25). Https://Doi.Org/10.2337/Diaclin.2 5.2 .66

Deepa, L., Murty, P., Reddy, M., \& Shetty, S. (2017). Assessment Of Awareness And Practice Of Foot Care And Physical Activity Among People With Type 2 Diabetes Attending A Tertiary Care Teaching Hospital. International Journal of Community Medicine And Public Health Int $J$ Community Med Public Health, 44 (9), 3218-3223. Https://Doi.Org/10.18203/23946040.Ijcmph20173816

Delamater, A. M. (2006). Improving 
Patient Adherence. Clinical Diabetes, 24(2), 71-77. Https://Doi.Org/10.2337/Diaclin.2 4.2.71

Diani, N., Waluyo, A., \& Sukmarini, L. (2013). Pengetahuan Klien Tentang Diabetes Melitus Tipe 2 Pendahuluan Metode, 16 (2), 120 127.

Dinas Kesehatan Provinsi Jawa Tengah. (2016). Profil Kesehatan Provinsi Jawa Tengah, 3511351 (24).

Frykberg, R. G., Zgonis, T., Armstrong, D. G., Driver, V. R., Giurini, J. M., Kravitz, S. R., Dan Wukich, D. K. 2006. Diabetic Foot Disorders: A Clinical Practice Guideline. The Journal Of Foot And Ankle Surgery 45(5).

Hokkam, E. N. (2009). Assessment Of Risk Factors In Diabetic Foot Ulceration And Their Impact On The Outcome of The Disease. Primary Care Diabetes, 3(4), 219224.

Https://Doi.Org/10.1016/J.Pcd.200 9.08.009

Hokkam Diabetes Federation (IDF). (2015). IDF Diabetes Atlas 7th Edition. Idf.Org. Https://Doi.Org/10.1289/Image.Eh p.V119.I03

Khamseh, M. E., Vatankhah, N., \& Baradaran, H. R. (2007). Knowledge And Practice Of Foot Care In Iranian People With Type 2 Diabetes. International Wound Journal, 4(4), 298-302. Https://Doi.Org/10.1111/J.1742481X.2007.00381.X

Lis, A., Gandini, A., Pranggono, E., \& Ropi, H. (2015). Pendidikan Kesehatan Terhadap Pengetahuan , Perilaku Dan Gula Darah Pada
Pasien Diabetes Mellitus Tipe 2. Husada Mahakam, III(9), 474483.

Lukitasari, D. A. (2013). Hubungan Tingkat Pengetahuan Dengan Kepatuhan Kontrol Pada Lansia Dengan Hipertensi Di Puskesmas Manisrenggo Klaten.

Moussa, M., Moussaandnaglaa, M., \& Mohamed, I. (2017). Effect Of Foot Self Care Program Among Diabetic Elderly Adults In Geriatrics Home, 6(3), 41-51. Https://Doi.Org/10.9790/19590603054151

Muflihatin, S. K., \& Saputra, R. I. (2016). Jurnal Ilmu Kesehatan Vol. 4 No. 2, Desember 2016, 4(2), 1-14.

Mulyadi, Rahman, F., Rosadi, D., Khairiyati, L., \& Musafaah. (2013). Risk Factors For Diabetes Mellitus Type 2 In The Working Area Of Public Health, (Dm), 510.

Natovich, R., Harman-Boehm, I., Margalit, D., Cukierman-Yaffe, T., \& Kushnir, T. (2017). Adherence To Self-Care Among Individuals With Diabetes With And Without Diabetic Foot Complications: Objective And Self-Report Measures. Diabetes Manag, 7(2), 234-239.

Notoatmodjo,S.(2010). Metodologi Penelitian

Kesehatan.Yogyakarta:Rieka Cipta.

PERKENI. (2015). Konsensus Pengelolaan Dan Pencegahan Diabetes Melitus Tipe 2 Di Indonesia 2015. Perkeni. Https://Doi.Org/10.1017/CBO978 1107415324.004

Purwanti, L. E., \& Nurhayati, T. (2017). 
Analisis Faktor Dominan Yang Mempengaruhi Kepatuhan Pasien DM Tipe 2 Dalam Melakukan Perawatan Kaki. Jurnal Ilmiah Kesehatan, 10(1), 44-52.

Putri, N. H. K., \& Isfandiari, M. A. (2013). Hubungan Empat Pilar Pengendalian DM Tipe 2 Dengan Rerata Kadar Gula Darah. Berkala Epidemiologi, 1(2), 234-243.

Sukmaningsih, W. R. (2016). Faktor Resiko Kejadian Diabetes Melitus Tipe II Di Wilayah Kerja Puskesmas Purwodiningratan Surakarta. Publikasi Ilmiah Jurusan Kesehatan Masyarakat Fakulta Ilmu Kesehatan Universitas Muhammadiyah Surakarta, 1, 16.

Trisnawati, S. K., \& Setyorogo, S. (2013).

Faktor Risiko Kejadian Diabetes Melitus Tipe II Di Puskesmas Kecamatan Cengkareng Jakarta Barat Tahun 2012. Jurnal Ilmiah Kesehatan, 5(1), 6-11.

Wahyuni, A., \& Arisfa, N. (2016). Senam Kaki Diabetik Efektif Meningkatkan Ankle Brachial Index Pasien Diabetes Melitus Tipe 2. Jurnal Ipteks Terapan, 2, 155-164. Retrieved From Http://Dx.Doi.Org/10.22216/Jit.20 15.V9i2.231

Waspadji, S. (2014). Kaki Diabetes. In S.Setati, I. Alwi, A. W. Sudoyo, \& M. Simadibrata (Eds.), Buku Ajar Ilmu Penyakit Dalam VI.(2),2367. Jakarta: Interna Publishing.

Windasari, N. N. (2014). Pendidikan Kesehatan Dalam Meningkatkan Kepatuhan Merawat Kaki Pada Pasien Diabetes Melitus Tipe II. Unpublished, (1), 1-5. Https://Doi.Org/10.1007/S13398-
014-0173-7.2

World Health Organization. (2016). Global Report On Diabetes. Isbn, 978, 88. Https://Doi.Org/ISBN 978 9241565257

Yoyoh, I., Mutaqqijn, I., \& Nurjanah. (2016). Hubungan Antara Perawatan Kaki Dengan Risiko Ulkus Kaki Diabetes Di Ruang Rawat Inap Rsu Kabupaten Tangerang, (2), 8-15. 